\title{
Touch sensitivity in Caenorhabditis elegans
}

\author{
Alexander Bounoutas • Martin Chalfie
}

Received: 25 October 2006 / Accepted: 31 October 2006 / Published online: 7 February 2007

(C) Springer-Verlag 2007

\begin{abstract}
The nematode Caenorhabditis elegans was the first organism for which touch insensitive mutants were obtained. The study of the genes defective in these mutants has led to the identification of components of a mechanosensory complex needed for specific cells to sense gentle touch to the body. Multiple approaches using genetics, cell biology, biochemistry, and electrophysiology have characterized a channel complex, containing two DEG/ENaC pore-forming subunits and several other proteins, that transduces the touch response. Other mechanical responses, sensed by other cells using a variety of other components, are less well understood in C. elegans. Many of these other senses may use TRP channels, although DEG/ENaC channels have also been implicated.
\end{abstract}

Keywords Mechanosensitivity - Sensory neurons · Mechanosensitive channel $\cdot$ Epithelial $\mathrm{Na}^{+}$channel . TRP channel

\section{Introduction}

The detection of mechanical forces is a basic sense present in virtually all organisms. Bacteria sense osmotic pressure, plants sense and respond to gravity, and humans have a variety of mechanosensory behaviors, including touch and

\footnotetext{
A. Bounoutas $\cdot$ M. Chalfie $(\square)$

Department of Biological Sciences, Columbia University, 1012 Fairchild, MC\#2446, 1012 Amsterdam Avenue, New York, NY 10027, USA

e-mail:mc21@columbia.edu

A. Bounoutas

e-mail: ab2057@columbia.edu
}

hearing. In fact, Kung [46] has argued that the sensing of mechanical force may be the most ancient of the senses. Despite their ubiquity and importance, these senses are more poorly understood at the molecular level than other senses like smell and vision.

Understanding mechanosensation in higher eukaryotes has proven especially difficult. Molecules needed for transducing mechanical force are thought to be present in low quantities; this rarity prevents isolation and identification of the molecules via biochemical means. Therefore, genetic approaches have been used to identify candidate molecules required for touch sensation. The first organism in which this approach was used was the nematode Caenorhabditis elegans.

C. elegans lends itself to easy genetic analysis. The animal has two sexes: self-fertilizing hermaphrodites, which allow easy maintenance of severely defective strains, and males, which allow cross-fertilization. In addition, much is known about $C$. elegans biology. Its entire genome has been sequenced [35], its entire cellular development from zygote to adult has been described [80, 81], and all 302 neurons of the hermaphrodite nervous system have been identified and their anatomical connections mapped by electron microscopy [91]. Because the worm is transparent, these neurons can be ablated to test their roles. Of particular importance for this review, $C$. elegans has several mechanosensory behaviors, including responses to gentle touch, harsh touch, and nose touch, food-mediated slowing, osmotic avoidance, and male mating behaviors [56].

In this review, we primarily discuss $C$. elegans gentle touch mechanosensation. Gentle touch sensitivity is usually tested by stroking the worm with an eyebrow hair attached to a toothpick. Touches to the anterior half of the worm cause the animals to reverse and move backward, while 
stimulating the tail causes the animal to accelerate forward [12]. More intense stimuli, such as prodding with a platinum wire, constitute harsh touch and are mediated by different sensory neurons than gentle touch mechanosensation $[12,90]$. The neurons involved in responding to gentle touch also respond to taps to the culture plate upon which the worms are grown. Plate tap produces a nondirectional mechanical stimulus on the worm and evokes a tap withdrawal reflex; young larvae move forward half the time, whereas adults almost always move backward [18]. Because tapping appears to activate both anterior and posterior responses simultaneously [59], the change in tap withdrawal as animals mature demonstrates a change in the reflex circuitry.

\section{Touch receptor neurons}

Six touch receptor neurons (Fig. 1a) sense gentle touch and plate tap $[12,93]$. Two bilaterally symmetric pairs of cells are located anterior of the vulva (ALML and ALMR) and in the tail (PLML and PLMR). These cells arise embryonically and have laterally-directed processes. A third pair of cells (AVM and PVM) originate from bilaterally symmetric precursors, but lie in different positions (in the mid anterior and posterior of the worm, respectively) because of the migrations of their precursors [80]. These cells arise after hatching and have processes that are located in the ventral cord.

The behavior of laser-ablated animals indicates that touch to the anterior half of the animal is sensed primarily by the ALM neurons in all stages and also by the AVM neuron in mature animals. Touch to the posterior half of the animal is sensed by the PLM neurons [13, 93]. The PVM neuron alone does not produce a response to touch or tap, but synapses formed by the neuron suggests that it may have a subtle role in anterior touch sensation [13].

As with most $C$. elegans neurons the touch receptor neurons have a very simple morphology [14]. Each of the six cells has a single anteriorly directed process that extends from the touch receptor cell bodies. All the cells, except for PVM, branch near the anterior end of the process. In addition, the PLM cells have single posteriorly directed processes (the ALM cells sometimes have a short posteriorly directed process, but when present, it is much shorter). The processes appear to have a dual purpose. First, they are likely to be the sensory endings of the neurons because touch is sensed over their entire lengths. The position of the touch receptor processes next to the cuticle [12] presumably puts it in an optimal position to detect external mechanical signals. Second, the processes make synaptic connections
Fig. 1 Touch receptor neurons needed to sense gentle touch stimuli. a Diagram of touch receptor neurons (blue) in $C$. elegans; adapted with permission from Chalfie and Sulston [12]. b Electron micrograph of a cross-section of a process of a touch receptor neuron. These cells contain specialized large-diameter microtubules (blue arrow) and are enveloped by an extracellular mantle (ECM) (red arrow); reproduced with permission from Chalfie and Sulston [12]. c Proteins required for mechanosensation in the touch receptor neuron include components of a $\mathrm{DEG} / \mathrm{ENaC}$ channel, tubulins that comprise the large-diameter microtubules, and molecules in the ECM; adapted with permission from O'Hagan and Chalfie [56]. d Components of the mechanosensory channel complex localize to discrete puncta along the touch neuron process, as visualized with MEC-4::GFP (false colored) Reproduced with permission from Emtage et al. [25]

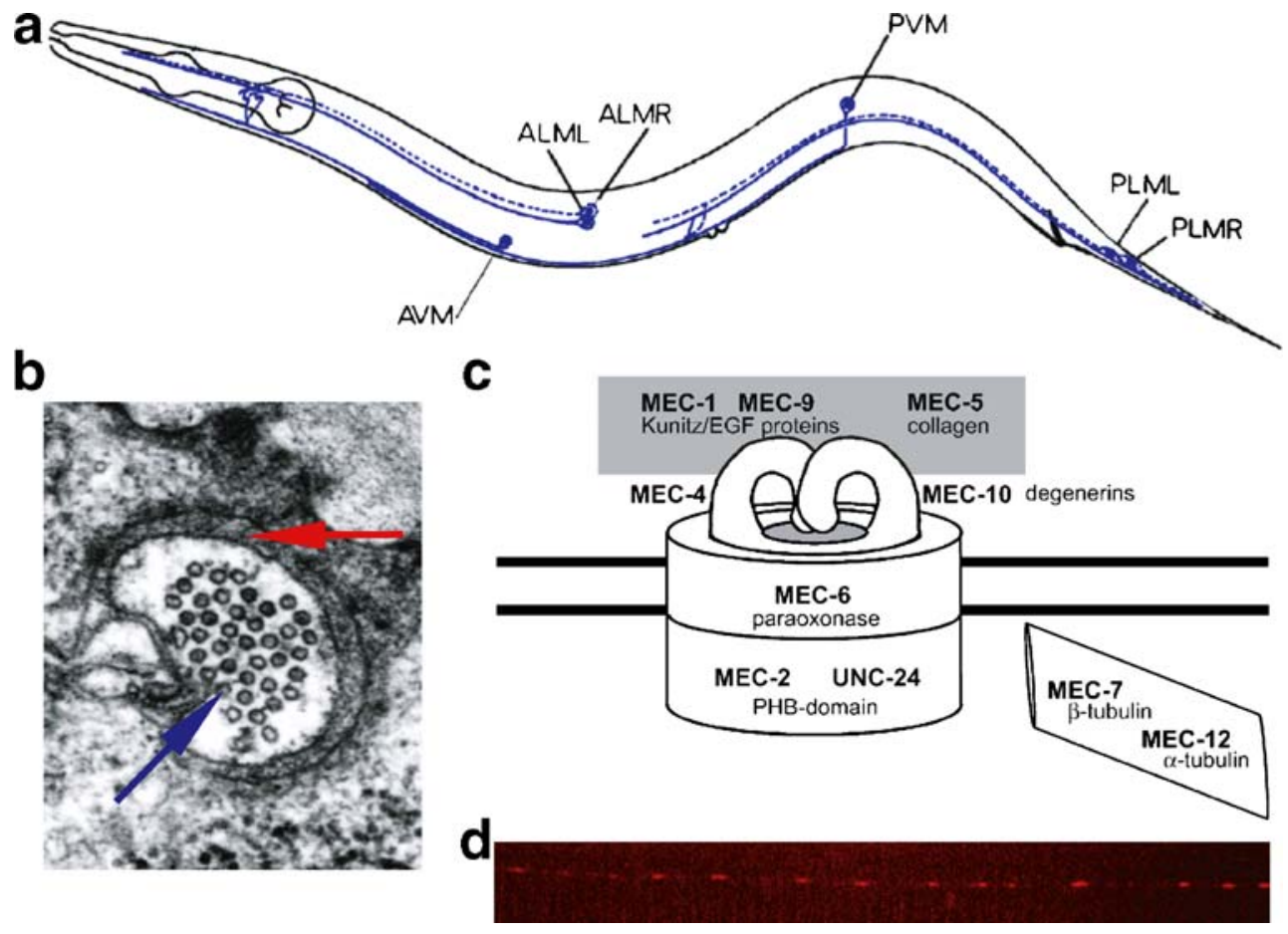


with interneurons, either directly or through their anterior branch [12].

All six neurons have common physical features that differentiate them from other neurons, including prominent extracellular matrix (called the mantle) that periodically enlarges along the process and large-diameter (15-protofilament) microtubules that fill it (Fig. 1b) [12, 14]. These cells are the only ones with these specialized microtubules.

\section{Proteins required for generation and differentiation}

Screens for mutants that are insensitive to gentle touch have identified genes necessary for both touch receptor neuron development and function. Most of the genes identified in these screens were designated as mechanosensory abnormal or mec $[10,12,78]$. Genes that are needed for the generation and differentiation of these cells are described in this section, whereas those needed for touch neuron function are described in the next section.

Several transcription factors are necessary for the production of the touch receptor neurons. Two genes, lin32 and $v a b-15$, are needed for the differentiation and division of the neuroblasts that give rise to the touch neurons. lin-32 encodes a basic helix-loop-helix protein; $v a b-15$ encodes a $m s h$-type homeobox gene [22, 100]. Mutations in either gene prevent the production of AVM, PVM, and the PLM neurons and affect the proper migration of the ALM neurons. lin-32 and vab-15 are partially redundant in the ALM cells because the double mutants lack all six touch receptor neurons [10, 12, 22]. LIN-32 (the protein product of the lin-32 gene) appears to act early in development to regulate neuroblast cell fate $[10,100]$. Because vab-15 is genetically redundant with lin-32 in ALM development, VAB-15 may act similarly [22].

unc-86, which encodes a POU-type homeodomain protein, affects later development in the lineages that give rise to the touch neurons [27]. unc-86 is expressed in the touch receptor neurons and their precursors, among other cells [26]; mutations in unc-86 affect the precursors so that the correct lineages are not followed and none of the six touch receptor neurons are made $[11,12]$.

The touch neurons require $u n c-86$ not only for their generation but also their differentiation [26]. UNC-86 activates expression of mec-3, another gene required for touch cell fate $[12,94]$. In mec-3 mutants, cells that normally become touch receptor neurons are present but do not undergo proper differentiation and lack the characteristic touch neuron features: they no longer have the 15protofilament microtubules or mantle, and the ALM cells develop a prominent posterior process [12]. The mec-3 gene encodes a LIM-type homeodomain protein that is expressed in the six touch neurons as well as the FLP and PVD neurons [89, 90]. UNC-86 and MEC-3 transcription factors bind cooperatively as heterodimers, increasing their DNA-binding specificity and stability [95]. UNC-86::MEC3 heterodimers then bind promoters of mec-3 and other genes, maintaining mec-3 expression and activating transcription of downstream genes necessary for touch receptor neuron function [24, 94]. The requirement for $m e c-3$ for touch neuron differentiation has been used to identify additional mec-3-dependent genes using DNA microarrays [99]. The roles of most of these new genes in touch sensitivity have not been tested.

The differentiation of touch receptor neurons is controlled not only transcriptionally, but also posttranscriptionally. Specifically, the mec- 8 gene appears to be needed for the correct splicing of the touch function gene mec-2 (Calixto et al., unpublished data). mec- 8 encodes a widely-expressed protein with two RNA recognition motifs and is known to be needed for correct mRNA processing in other tissues $[53,96]$. The number of genes requiring mec-8-processing in the touch receptor neurons is not known.

\section{Proteins required for mechanosensation}

Differentiated touch receptor neurons express several genes required to sense gentle touch and tap. The products encoded by these genes include subunits of a mechanoreceptor channel complex, components of the extracellular matrix, tubulins that form the 15 -protofilament microtubules, and additional proteins of unknown function (Fig. 1c).

The mechanoreceptor channel complex contains at least five proteins that are needed to transduce the touch stimulus. The main pore-forming subunits of this complex are encoded by the mec- 4 and mec-10 genes. MEC-4 and MEC-10 are degenerins, a class of ion channels in $C$. elegans named after the neuronal degeneration phenotype caused by gain-of-function alleles [16, 21, 38]. Degenerins are part of the degenerin/epithelial sodium channel (DEG/ $\mathrm{ENaC}$ ) protein superfamily found in invertebrates and vertebrates. DEG/ENaC proteins form ion channels that conduct sodium and are blocked by the diuretic amiloride $[2,33,44]$. Whereas C. elegans degenerins function in mechanosensation and, perhaps, proprioception [84], DEG/ $\mathrm{ENaC}$ channels in vertebrates have also been implicated in nociception, sodium homeostasis, regulation of the composition and volume of lung fluids, and memory and learning $[44,45]$.

$\mathrm{DEG} / \mathrm{ENaC}$ proteins contain cytoplasmic $\mathrm{NH}_{2}$-terminal and $\mathrm{COOH}$-terminal ends, two transmembrane domains, and an extracellular loop containing two cysteine-rich 
domains (CRDs). The extracellular loops in degenerins (as represented by six of the $23 \mathrm{C}$. elegans DEG/ENaC proteins) have an additional CRD as well as an extracellular regulatory domain (ERD) located $\mathrm{N}$-terminal to the other CRDs (Fig. 2) [44]. The second transmembrane domain (TMII) and the sequence preceding it are thought to contribute to the pore of the channel; mutations in these regions cause constitutive channel activity, blockage of the constitutive activity, or changes in ion selectivity $[36,37$, 57]. The mutations that cause constitutive channel activity were first identified as changes in MEC-4, MEC-10, and other $C$. elegans degenerins that cause neurodegeneration $[16,21,38]$. Substitutions of large-side chain residues for an alanine in the region preceding TMII cause hyperactivation and toxic influx of ions [21, 36, 75]. Additional degeneration-causing and gain-of-function mutations have been found affecting the degenerin ERD, suggesting that this region of the extracellular loop gates channel activity $[30,84]$. The most C-terminal CRD, which is highly conserved, exhibits similarity to venom neurotoxin, suggesting a possible role in modulating $\mathrm{DEG} / \mathrm{ENaC}$ channel gating [83]. mec-4 mutations in this region disrupt channel function and may affect appropriate gating [37]. Finally, parts of the cytoplasmic $\mathrm{COOH}$-terminal domain of MEC-4 may be required for channel trafficking or maintenance of the channel in the cell surface [67].

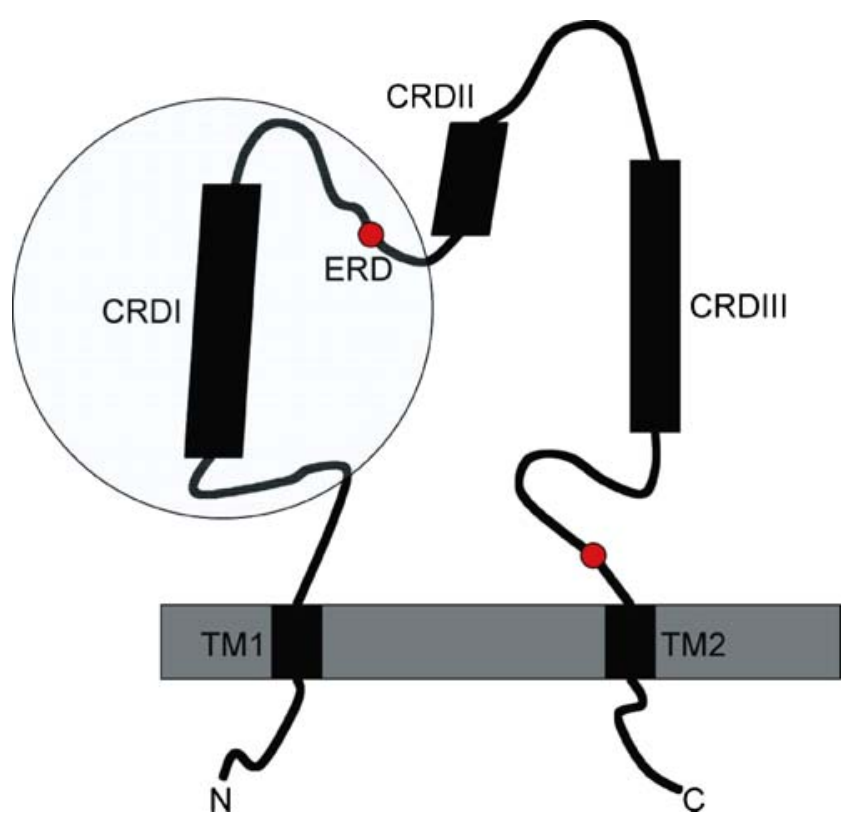

Fig. 2 Conserved domains in $\mathrm{DEG} / \mathrm{ENaC}$ channels. DEG/ENaC channels have cytoplasmic $\mathrm{N}$ - and $\mathrm{C}$-terminal ends, two transmembrane (TM) domains, and two cysteine-rich domains (CRD). Degenerins such as MEC-4 have an additional CRD domain as well as an extracellular regulatory domain (ERD), shown in the shaded circle. Mutations in the ERD and in the pore forming residues preceding TM2 (red) can cause neurodegeneration. Figure redrawn with permission from Kellenberger and Schild [44]
Substantial evidence supports the idea that thw mec-4and mec-10-encoded degenerins transduce gentle touch. Mutations in either gene produce touch insensitivity [12], and gain-of-function mutations as described above lead to touch receptor neuron degeneration [16, 21, 30, 38]. Both genes are coexpressed in the six touch neurons [38]. Along the touch neuron process, MEC-4 localizes to discrete puncta where mechanosensory proteins are believed to exist as a complex (Fig. 1d) [17]. When expressed in heterologous systems, MEC-4 and MEC-10 coimmunoprecipitate with each other and with other putative mechanosensory channel subunits [17, 31]. In frog oocytes, expression of the mutant form of MEC-4 that produces degeneration, MEC$4 \mathrm{~d}$, can induce an amiloride-sensitive sodium current. MEC-10d alone cannot generate a current in the oocytes, but when coexpressed with MEC-4d, it becomes a part of the channel and modifies the current's properties [31]. These data are consistent with the fact that in vivo, mec-4 (d) produces strong degeneration independent of mec-10, while mec-10(d) degeneration is less frequent and requires mec-4, and suggest that MEC-4 and MEC-10 have functional differences [38]. Finally, in vivo electrophysiology recordings of touch receptor neurons demonstrate that MEC-4 and MEC-10 transduce gentle touch stimuli ([57], see below).

In addition to the MEC-4 and MEC-10 pore-forming subunits, the mechanoreceptor channel complex includes proteins encoded by mec-6, mec-2, and unc-24. MEC-6, a transmembrane protein that is similar to mammalian paraoxonases, is widely expressed, including in the touch receptor neurons. In the touch neurons, MEC-6 colocalizes with MEC-4 puncta along the neuronal process. MEC-6 coimmunoprecipitates with the degenerins and other channel subunits [17], and mutations in mec-6 produce touch insensitivity [12], eliminate MEC-4 puncta [17] and suppress mec-4(d)- and mec-10(d)-induced degeneration $[16,38]$. Additionally, MEC-6 increases MEC-4d currents expressed in frog oocytes [17]. These results suggest that MEC-6 is a subunit of the mechanosensory complex required for proper channel localization, formation, and function. Because it is widely expressed in other tissues and required for degeneration caused by gain-of-function mutations in other degenerins, MEC-6 may play similar roles in other DEG/ENaC channels [16, 30, 50, 73].

mec-2 and unc-24 encode PHB (prohibitin homology)domain membrane proteins $[3,39]$. The PHB domain is a 150 amino acid domain found in a large number of proteins including stomatin, flotillin, prohibitin, and podocin in vertebrates. Stomatin may regulate ion permeability because loss of stomatin in red blood cells of individuals with hereditary stomatocytosis leads to cell lysis [76]. Stomatin, podocin, MEC-2, UNC-24, and several other PHB-domain proteins have a hydrophobic 
region $\mathrm{N}$-terminally adjacent to the PHB domain $[3,8,39$, 77]. This domain in MEC-2, stomatin, and podocin attaches the proteins to the inner leaflet of the plasma membrane [40].

MEC-2 and UNC-24 are expressed in the touch receptor neurons, while UNC-24 is also expressed in other neurons and is required for proper movement and coordination [3, 39]. Both proteins colocalize with MEC-4 puncta and coimmunoprecipitate with MEC-4 and other mechanoreceptor channel subunits [17, 31, 98]. While both MEC-2 and UNC-24 appear to be part of the touch receptor complex, the effects of their loss on mechanosensation differ. mec-2 null mutants are completely touch insensitive [12], whereas unc-24 mutants display only subtle defects in touch sensitivity [98]. This difference is also reflected in frog oocytes, where MEC-2 increases MEC-4d currents 40fold [31], while UNC-24 has no affect on MEC-4d current alone and decreases it by $30 \%$ in the presence of MEC-2 [98].

Proper function of both MEC-2 and UNC-24 require the conserved PHB domain. In MEC-2, the domain is required for homooligomerization, localization to puncta, and amplification of MEC-4d currents in frog oocytes [98]. Recently, MEC-2 has also been shown to bind cholesterol; this binding requires the PHB domain and five amino acids in the adjacent hydrophobic region [40]. In HEK 293T cells, expression of MEC-2 can bind and recruit cholesterol to rat $\alpha \mathrm{ENaC}$ (a $\mathrm{DEG} / \mathrm{ENaC}$ protein whose TM2 domain can substitute for that of MEC-4 in vivo [36]), and MEC-2 probably plays a similar role in C. elegans touch receptor neurons. While cholesterol is not required for MEC-2 multimerization or association with DEG/ENaC proteins, gentle touch sensitivity in worms is dependent on sterols [40]. The PHB domain of UNC-24 has not been tested for the ability to bind cholesterol, but it is necessary for the association of UNC-24 with other channel subunits [98]. UNC-24 also contains a nonspecific lipid-transfer domain $[3,72]$. Such a domain could be needed for the insertion of cholesterol into the membrane. The association of these proteins with themselves, the channel pore subunits, and cholesterol might regulate channel activity by organizing the lipid environment around the mechanoreceptor complex.

In addition to encoding genes that form the mechanosensory channel complex at the membrane, touch sensitivity genes also encode components of the extracellular matrix (ECM, mantle). Three such genes are mec-1, mec-5, and mec-9. mec- 1 and mec-9 encode proteins with EGFand Kunitz-like domains that are expressed and secreted by the touch neurons $[23,25]$, while mec-5 encodes a novel collagen generated by surrounding cells [23]. Both MEC-1 and MEC-5 proteins colocalize with the MEC-4 puncta along the touch neuron process, suggesting that they are concentrated around the mechanoreceptor channel complex [25].

The punctate distribution of the mechanoreceptor channel complexes requires mec-1, mec-5, and mec-9. Mutations in any one of these genes abolish proper localization of both mechanosensory channel subunits (MEC-4 and MEC-2) and ECM proteins MEC-1 and MEC-5 to their characteristic puncta along the process [25, 97], but loss of the channel subunits does not affect the localization of MEC-1 and MEC-5 puncta [25]. Because the puncta appear to align with annuli, the periodic ridges of the cuticle created by the hypodermis, the hypodermis probably contributes to the distribution of the puncta [25].

MEC-1 appears to have several functions in the touch receptor neurons. Complete loss of mec-1 produces touch insensitive animals whose touch processes lack much of the ECM and are no longer attached to the body wall $[12,25]$. The attachment and ECM defects can be separated by mutations from touch insensitivity; partial loss-of-function mutations of mec-1 result in completely touch-insensitive animals that have normal appearing ECM, puncta, and attachment. Moreover, mutations in the hemicentin him-4 gene also prevent touch cell process attachment but have little effect on touch sensitivity [87].

The touch receptor neurons are distinguished from other cells in C. elegans by having 15 -protofilament rather than 11-protofilament microtubules [15]. mec-7 and mec-12 encode the $\beta$-tubulin and $\alpha$-tubulin subunits of these largediameter microtubules, respectively [29, 69]. Mutations in these genes and drugs that depolymerize the specialized microtubules cause animals to become touch insensitive [12, 15]. The cell processes are still present in the mutants because 11-protofilament microtubules have replaced the 15protofilament microtubules and allow process outgrowth [15]. The 15-protofilament microtubules are arranged in bundles and fill the axon process, and their distal ends appear to associate with the plasma membrane [14].

The large-diameter microtubules appear to have multiple roles in the touch receptor neurons, so their specific role in mechanosensation is unclear. For example, mutations in these genes can affect the distribution but not the production of MEC-2 and MEC-4 puncta, restricting them to the cell body and proximal parts of the axon and suggesting a role of microtubules in transport of the channel complexes in the process $[25,39]$. We have recently found, however, conditions in which the microtubules can be disrupted in adults (Bounoutas and Chalfie, unpublished data). These animals have a normal distribution of puncta but are touch insensitive. Thus, the microtubules may have a direct role in mechanosensation.

Additional proteins required for touch sensitivity have been identified but not fully characterized. Mutagenesis screens for touch insensitivity identified alleles for mec-14, 
mec-15, mec-17, and mec-18, and all but mec-15 have been cloned. mec-14 encodes an oxido-reductase-like protein expressed in the six touch receptor neurons (Chalfie et al., unpublished data). Because MEC-14 is somewhat similar to the $\beta$-subunit of the Drosophila shaker $\mathrm{K}^{+}$channel, an intriguing speculation is that it regulates the mechanoreceptor channel complex. mec-17 encodes a novel protein with no readily identifiable motifs [98]. Finally, mec-18 encodes a protein similar to plant firefly luciferase and plant $\mathrm{CoA}$ ligase ( $\mathrm{Gu}$ and $\mathrm{MC}$, unpublished data).

\section{Mechanoreceptor current and calcium influx}

A better understanding of touch receptor function has come from in vivo electrophysiology recordings and from calcium imaging of the neurons. Using techniques developed for patch-clamp recording from $C$. elegans neurons [32, 52], PLM neurons were recorded from while mechanical stimuli were applied to the posterior body wall [57]. The onset of stimuli produced a mechanoreceptor current (MRC) that peaked rapidly and then decayed during continued force; removal of force produced an additional MRC of equal amplitude (Fig. 3). Forces as small as $100 \mathrm{nN}$ generated MRCs, and increasing the amount of force increased the amplitude of the current (responses saturated for forces exceeding $1-2 \mu \mathrm{N}$ ) [57]. Although worms habituate to repeated gentle touch and plate tap $[12,60]$, the size of the MRCs did not decrease with repeated stimuli, suggesting that habituation occurs subsequent to the generation of the MRC. Finally, the MRCs were carried primarily by $\mathrm{Na}^{+}$and were reversibly blocked by amiloride, as expected if they require the MEC-4/MEC-10 DEG/ENaC channel [57].

Electrophysiology recordings of touch receptor neurons allow direct examinations of the effects of mutations on mechanosensory transduction. Null mutations in mec-2, mec4 , or mec-6 eliminate MRCs, suggesting that each of these subunits is needed for channel function [57]. These mutations do not affect other currents in the touch receptor neurons, showing specificity for affecting MRCs [57, 82]. More significantly, point mutations in mec-4 and mec-10 that modify the selectivity of the degenerin channel alter the properties of the MRC. This alteration and the rapid onset of the effect $(<0.5 \mathrm{~ms})$ argue that the MEC-4 channel complex is transducing touch in these cells [57]. In contrast to the loss of MRCs when channel subunits are mutated, MRCs are reduced ( 17-fold) but not abolished when the mec-7 $\beta$-tubulin is absent [57]. These data suggest that the microtubules may not be essential for transduction.

Depolarization by the MRC leads to a subsequent calcium influx into the touch receptor neurons. Calcium imaging experiments of ALM neurons in vivo show that this influx is dependent on mec-4 and mec-2 as well as

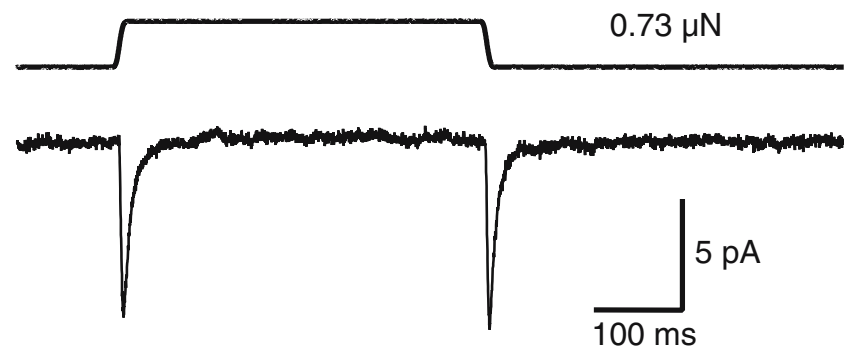

Fig. 3 Electrophysiological recording of a mechanoreceptor current (MRC). Both onset and offset of force (top trace) to the touch receptor neuron generates a current response (bottom trace). Figure reproduced and modified with permission from O'Hagan et al. [57]

egl-19, which encodes an $\alpha$-subunit of an L-type voltagegated calcium channel [82]. Imaging of cultured touch receptor neurons also suggests that UNC-36, an $\alpha_{2} / \delta$ subunit of L-type channels, may function as an accessory subunit to enhance calcium influx and voltage sensitivity [28]. The role of this calcium influx in response to the MRC is unclear. egl-19 reduction-of-function mutants and unc-36 null mutants are not fully touch sensitive; in addition, they have subtle defects in touch neuron migration and axon guidance that preclude attributing the cause of touch insensitivity to reduced calcium influx [28]. C. elegans lacks voltage-gated sodium channels, so voltage-gated calcium channels may contribute to the propagation of action potentials down the touch neuron process. The influx of extracellular calcium may also act on downstream secondary messengers in the neuron, triggering neurotransmitter release to targets in the touch reflex circuit that inhibit the opposite touch response and regulate habituation.

\section{Models for mechanosensation}

The initial model for mechanosensation in the touch receptor neurons was a dual-tether model (Fig. 4a) [39]. In this model, the mechanoreceptor channel complex is tethered intracellularly by the large-diameter microtubules and extracellularly by the proteins in the ECM. Application of force to the membrane would displace the microtubules, producing tension on the channel attached to the ECM. Movement of the channel between these two attachment points would then force the channel open.

Although the microtubules associate with the plasma membrane [14] and can affect transport of channel subunits throughout the axon $[25,39]$, recent evidence casts doubt on their role as intracellular tethers. Null mutations in $m e c-7$ and mec-12 do not eliminate MRCs [57], suggesting that the large-diameter microtubules are not essential for the gating of the channel. Furthermore, stretching of the channel because of the displacement of the two tethering points seems unlikely to produce equal responses when force is both applied and removed, although this is what is seen in vivo [57]. 
We currently favor a model, derived from suggestions made by Kung [46], in which the channel complex is only tethered extracellularly. In this model, movement of the channel relative to the membrane, for example by pushing the channel into the cell when the animal is touched, would change the forces in the bilayer on the channel. These changes in force would cause the channel to open in analogy with the MscL mechanosensory channel in bacteria (Fig. 4b). The rapid adaption seen when animals are touched could result from the redistribution of forces in the bilayer. Elastic changes would again displace the channel complex when the force is removed leading to a second MRC that would quickly adapt. The role of the microtubules in this model is unclear. One possibility is that the microtubules organize the cell cortex so that movement of the bilayer is restricted. Similarly, the ECM outside the puncta might also constrain the movement of the membrane. These constraints could slow adaptation.

\section{Touch reflex circuitry}

Sensation of mechanical stimuli by the touch receptor neuron triggers changes in locomotion and other behaviors. Movement away from the touch stimulus is controlled by a three-neuron reflex circuit. C. elegans locomotion results from alternating contraction of dorsal and ventral wall body muscles. This muscle contraction is activated by ventral cord motor neurons (A motor neurons for backward movement and B motor neurons for forward movement), which in turn are regulated by four pairs of interneurons that extend throughout the ventral cord (AVA and AVD for backward movement; AVB and PVC for forward movement) [13]. The touch neurons form gap junctions with these interneurons to activate movement away from the touch stimulus (anterior touch neurons to AVD and posterior to PVC; secondary connections involve the other interneurons) [13]. To prevent simultaneous activation of both forward and reverse responses, anterior and posterior touch neurons also form putative inhibitory glutamatergic synapses with the interneurons activated by the other touch neurons (anterior touch neurons to PVC and posterior with AVD) $[13,47]$.

The relative strength of the motor circuit appears to change during development as seen by the response to plate-tap, which produces a nondirectional stimulus that presumably activates both the anterior and posterior touch response [93]. In early larva, C. elegans responds to plate tap by either moving forward or reversing at equal frequencies, suggesting the head and tail-touch circuits display equal strength and sensitivity. However, older animals almost always reverse, pointing to a developmental preeminence of the anterior touch circuit that corresponds to the rise of the postembryonic touch receptor neurons AVM and PVM [18].

In addition to locomotion, touch sensed by the touch receptor neurons modulates feeding behaviors, egg laying,
Fig. 4 Models of mechanotransduction in the touch receptor neurons. a Duel-tether model, in which the channel complex is attached to both the ECM and the large-diameter microtubules. In this model, separating the two tethering points forces the channel open. b A single-tether model of mechanosensation. In this model, displacement of the surrounding lipid bilayer around the channel produces forces that change the conformation state of the channel a



b

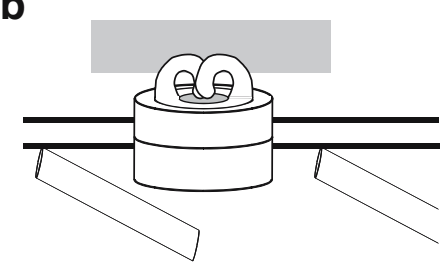

PULL UP
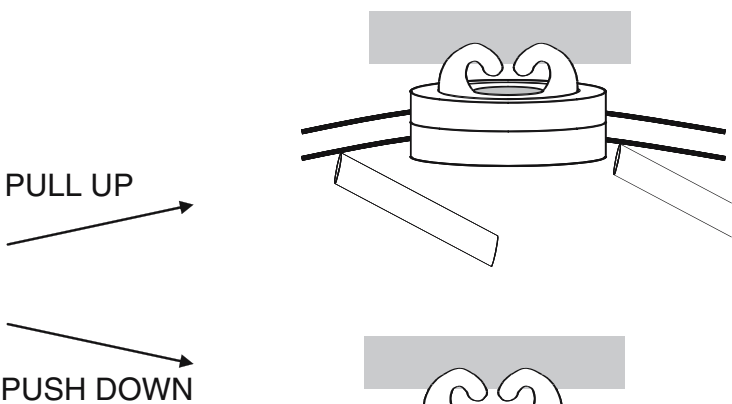

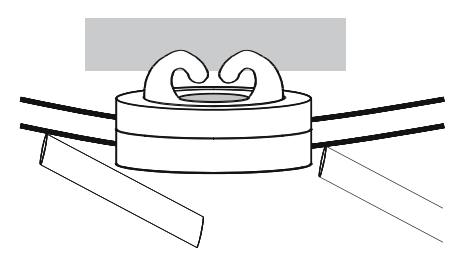


and defecation. C. elegans slows upon encountering bacterial food, a texture-sensing behavior requiring the dopaminergic CEP, ADE, and PDE neurons [68]. The touch neurons synapse onto these neurons [13] and may override their signaling in preference of moving away from the touch stimulus [56]. Stimulating touch receptor neurons also suppresses pharyngeal pumping and head oscillations in foraging behavior. The mechanism for suppressing pharyngeal pumping is unknown, though the touch neurons form connections with PVR neurons that synapse onto neurons in the pharynx [13]. Suppression of head oscillations results from anterior touch stimulation of the AVD and AVA interneurons, which trigger RIM neurons to release tyramine that inhibits motor neurons and contraction of muscles radially surrounding the base of the head [1]. In both cases, the feeding behavior of the worm is suspended as touch avoidance becomes paramount. Touch stimulation also suppresses egg-laying behavior. Egg laying requires HSN neurons, which receive chemical synapses from PLM neurons that may inhibit their function [13]. Finally, touch stimulation also resets the defecation cycle of the animal [49], though no intermediate neural connections have been identified.

\section{Habituation}

The response to gentle touch decreases as C. elegans is repeatedly touched $[12,60]$. This phenomenon is known as habituation. Habituation to gentle touch has been studied primarily by Catharine Rankin and her colleagues using the tap-withdrawal response [65]. Plate tap causes mature animals to reverse, and the frequency and distance of reversals diminish progressively with repeated taps. By measuring the distance of the reversals, habituation of the tap withdrawal response can be quantified [60]. This habituation depends on the frequency of the stimuli; animals habituate faster and more completely if taps are presented at a short interstimulus interval (ISI), such as every $2 \mathrm{~s}$, than if taps are presented at a longer intervals, such as $1 \mathrm{~min}$ [61]. Worms trained at shorter ISIs spontaneously recover from habituation quicker than worms trained at longer ISIs. These results suggest that the mechanisms of habituation for tap withdrawal response differ for short and long ISIs [61, 65]. Training C. elegans with blocks of taps at longer ISIs produces long-term memory (LTM) for habituation that can be retained in optimal conditions for about $24 \mathrm{~h}$. This memory cannot be generated with training blocks of short ISIs and can be disrupted by heat-shocking the animals in between blocks of stimuli [6, 65]. C. elegans are also susceptible to context conditioning, as plate tap training at long ISIs can be associated with other environmental cues to increase retention of habituation [58].
The mechanisms behind habituation to tapping are not fully understood. In vivo recordings from touch receptor neurons show that repeated stimuli do not decrease MRC amplitude, suggesting that habituation results from signals further downstream in the touch neurons themselves or postsynaptic to the neurons [57]. Because the chemical synapses between the touch neurons and interneurons involved in gentle touch mechanosensation appear to be glutamatergic in nature, habituation studies have focused on genes involved in glutamate transport and reception. eat-4, which encodes a protein with homology to rat brainspecific sodium-dependent inorganic phosphate cotransporter (BNPI), is expressed in touch receptor neurons [47]. In rat hippocampal neurons, BNPI transports glutamate into synaptic vesicles [7], and eat-4 presumably plays a similar role in the presynapses of touch receptor neurons. eat-4 mutants display faster than normal habituation of responses to plate-tap at all ISIs, slower spontaneous recovery, and an inability to produce LTM [62, 64]. Meanwhile, $g l r-1$ encodes a non-NMDA glutamate receptor expressed in all four interneurons (AVA, AVB, AVD, and PVC) that synapse with the touch receptor neurons, and mutations in $g l r-1$ also block LTM of habituation [63]. It is interesting to note that tap training of $C$. elegans modifies the density of postsynapse GLR-1 of the interneurons [63, 66]. These results suggest that glutamatergic transmission from the touch neuron to interneuron plays an important role in habituation.

Dopamine, which had previously not been implicated in gentle touch mechanosensation behavior, also affects habituation of the tap withdrawal reflex. ALM and PLM neurons express the dopaminergic receptor gene dop-1, and mutations in the gene cause the worm to habituate faster than normal in response to plate tap. This effect of dop-1 on habituation is specific to the touch receptor neurons, as a wild-type copy of the gene expressed under a touch neuron-specific promoter rescues the habituation defect in dop-1 mutants [68]. The touch receptor neurons synapse onto dopamine producing neurons (CEP, ADE, and PDE) [13], and synaptic input from the touch neurons could control their release of dopamine. Touch receptor neurons are presynaptic to the dopaminergic neurons, but dopamine may act as a neurohumoral agent or even be secreted extrasynaptically. The resulting feedback loop between touch neurons and dopaminergic neurons may modulate habituation of gentle touch mechanosensation [68].

\section{Other mechanosensory behaviors}

Although the response to gentle touch is the best understood mechanosensory behavior in C. elegans, other mechanosensory behaviors have also been examined. These 
behaviors include withdrawal from nose touch [20] and harsh touch to the body [12], texture-mediated slowing in the presence of food [70], mechanical detection of hermaphrodites by males during mating [51], and responses to body stretch (proprioception) [48, 84]. Some of these behaviors are thought to involve $\mathrm{DEG} / \mathrm{ENaC}$ channels, whereas others appear to require transient receptor potential (TRP) channels.

Nose touch, which is sensed by three types of ciliated neurons in the head, the ASH, FLP, and OLQ cells [43], may utilize both types of channel proteins. Two TRPV proteins, OSM-9 and OCR-2, are required for nose touch; they are coexpressed and possibly interact in the ASH neurons $[19,85]$. OSM-9 is also expressed in the FLP and OLQ neurons. In OLQ neurons, OSM-9 may form a heteromeric channel with another TRPV protein, OCR-4 [85]. Several DEG/ENaC proteins are expressed in these cells as well (UNC-8 in ASH and FLP neurons; DEL-1 and MEC-10 in FLP neurons) [38, 84], but their role, if any, in nose touch is not known.

Sensation of harsh body touch requires the PVD neurons [90]. These two nonciliated neurons, which lie between the midbody and the tail, extend long anterior and posterior processes that extend almost the entire length of the worm [92]. As the animal matures, these processes develop elaborate dentritic branches that cover most of the surface of the animal, giving them the appearance of multidendritic cells in other organisms [86]. The molecular machinery involved in sensing harsh touch is unknown. The degenerin MEC-10 is expressed in PVD neurons [38], but mec-10 mutations do not abolish sensitivity to harsh touch to the body [90]. One TRPV protein, OSM-9, is expressed in PVD cells, but the effect of its loss on the harsh touch response has not been reported.

C. elegans slows when it encounters a bacterial lawn or a patch of Sephadex beads the same size as bacteria, and this slowing is thought to be a response to surface texture. The ability to sense these textural differences requires the eight dopaminergic ADE, CEP, and PDE neurons [70]. Four CEP neurons are found in the head and extend ciliated sensory processes to the tip of the nose; pairs of ADE and PDE neurons are positioned in the head and posterior to the midbody, respectively, and send ciliated processes along the body's lateral midlines [78, 91]. These neurons express the TRPN channel TRP-4 [48]. The trp-4 gene is an ortholog of the fruitfly and zebrafish nотрC genes [74, 88]. Because trp-4 mutants do not slow on entering a bacterial lawn [48], TRP-4 may have a role in transducing textural stimuli.

Male mating behavior requires a series of movements of the male tail, including contact with the hermaphrodite, sensing vulva location, insertion of spicules into the vulva, and sperm release [51]. This behavior is carried out by 87 neurons exclusive to the male; 42 of these neurons are ciliated neurons in the tail and many of these may be mechanoreceptors [79]. Two TRPP proteins, the polycystinlike proteins LOV-1 and PKD-2, are expressed in a subset of these neurons and required for male mating response and vulva location $[4,5,54]$. The human polycystins, PC-1 and PC-2, the respective homologs of C. elegans LOV-1 and PKD-2, are defective in inherited polycystic kidney disease [41]; they localize to primary cilium of kidney epithelial cells and sense fluid sheer stress, presumably as a heteromeric channel complex [55]. LOV-1 and PKD-2 colocalize at the cilia of certain male-specific neurons in the tail [4] and may interact similarly to their human homologues to transduce mechanical stimuli during male mating.

C. elegans moves by bending its body in a sinusoidal wave. The shape of the sine wave is affected by several mutations, which have been hypothesized as interfering with proprioception, the ability to sense relative body positioning and stretch. One such gene is trp-4 [48]. As previously mentioned, TRP-4 is expressed in the dopaminergic neurons required for food-mediated slowing, but it is also expressed in the DVA interneuron [88]. The DVA cell body is located in the head, but it sends a process that extends for the entire length of the ventral cord [91]. trp-4 mutants bend their bodies deeper and more frequently than wild-type animals, and these defects can be rescued by expressing TRP-4 exclusively in the DVA neuron [48]. In addition, expression of the calcium sensor G-CaMP shows that body bends trigger a significant $\mathrm{Ca}^{2+}$ spike in the DVA, strongly suggesting that the DVA neuron senses bodystretch [48].

Another potential candidate for sensing proprioreception is the UNC-8 degenerin. UNC-8 is expressed in several neurons including the VA and VB motor neurons, which have regions of long, undifferentiated processes that may act as stretch receptors [84, 91]. While no imaging or recordings from VA and VB motor neurons in response to bending have been done, the neurons also express another degenerin DEL-1, which may interact with UNC-8 to form a heterologous mechanosensitive channel [84]. Unlike trp-4 mutants that display deeper body bending, unc- 8 mutants demonstrate more shallow body bends compared to wildtype worms [84]. Thus, if UNC-8-expressing motor neurons do function in proprioreception, they may act opposite to the TRP-4/DVA system to promote instead of inhibit C. elegans body bending [71].

\section{Future directions}

Although C. elegans has proven to be a very useful model for the study of mechanically driven senses, much work remains. Much of the essential transduction machinery has 
been identified for the response to gentle touch, but several problems exist. First, the nature of the mechanosensory complex is not completely understood. Although we know that five proteins form the channel complex, we do not know their stoichiometry or structure, and we do not know what other proteins are required. Screens for touch-insensitive mutants have identified many genes whose products are needed for touch sensitivity, but even though these screens are saturated, they cannot give a complete picture of the genes needed for touch sensitivity. Microarray analysis of RNAs expressed in the touch receptor neurons have provided many more candidate genes [99], but their importance in transduction has not been determined. Second, we do not know how that channel complex interacts with the ECM, nor how the ECM is structured. Third, we do not know how the association of cholesterol (or other sterols) with the channel complex affects its activity. Fourth, the role of the 15protofilament microtubules in mechanosensation remains to be elucidated. Fifth, and perhaps most important, we do not know exactly how touch is transduced by the channel complex.

For the other mechanically stimulated senses in $C$. elegans, the main area of future research will be the determination of the molecular bases of transduction. Although the sensory neurons and putative channels responsible for many of these behaviors have been identified, the means by which they sense mechanical stimuli has yet to be ascertained. Genetic approaches, using both classical procedures [9] and improved RNA interference methods [42], as well as DNA microarray methods (e.g., [99]) should provide additional candidates for components of the transduction machinery in these cells. Wild-type and mutant strains can then be analyzed by calcium imaging, as has been done with the ASH neurons needed for nose touch [34] and the DVA neuron needed for proprioreception [48], and direct electrophysiological recording to obtain a description of the mechanosensory currents in these sensory neurons.

The study of gentle touch in C. elegans has identified $\mathrm{DEG} / \mathrm{ENaC}$ channels as transduction channels for mechanosensation. This work also indicates that the sensing of mechanical force requires a rather complex molecular apparatus at the cell membrane. Future work will determine whether the lessons learned in C. elegans are applicable to mechanosensation in other organisms.

\section{References}

1. Alkema MJ, Hunter-Ensor M, Ringstad N, Horvitz HR (2005) Tyramine Functions independently of octopamine in the Caenorhabditis elegans nervous system. Neuron 46:247-260
2. Alvarez de la Rosa D, Canessa CM, Fyfe GK, Zhang P (2000) Structure and regulation of amiloride-sensitive sodium channels. Annu Rev Physiol 62:573-594

3. Barnes TM, Jin Y, Horvitz HR, Ruvkun G, Hekimi S (1996) The Caenorhabditis elegans behavioral gene unc-24 encodes a novel bipartite protein similar to both erythrocyte band 7.2 (stomatin) and nonspecific lipid transfer protein. J Neurochem 67:46-57

4. Barr MM, DeModena J, Braun D, Nguyen CQ, Hall DH, Sternberg PW (2001) The Caenorhabditis elegans autosomal dominant polycystic kidney disease gene homologs lov-1 and $p k d-2$ act in the same pathway. Curr Biol 11:1341-1346

5. Barr MM, Sternberg PW (1999) A polycystic kidney-disease gene homologue required for male mating behaviour in $C$. elegans. Nature 401:386-389

6. Beck CD, Rankin CH (1995) Heat shock disrupts long-term memory consolidation in Caenorhabditis elegans. Learn Mem 2:161-177

7. Bellocchio EE, Reimer RJ, Fremeau RT Jr, Edwards RH (2000) Uptake of glutamate into synaptic vesicles by an inorganic phosphate transporter. Science 289:957-960

8. Boute N, Gribouval O, Roselli S, Benessy F, Lee H, Fuchshuber A, Dahan K, Gubler MC, Niaudet P, Antignac C (2000) NPHS2, encoding the glomerular protein podocin, is mutated in autosomal recessive steroid-resistant nephrotic syndrome. Nat Genet 24:349 354

9. Brenner S (1974) The genetics of Caenorhabditis elegans. Genetics 77:71-94

10. Chalfie M, Au M (1989) Genetic control of differentiation of the Caenorhabditis elegans touch receptor neurons. Science 243:1027-1033

11. Chalfie M, Horvitz HR, Sulston JE (1981) Mutations that lead to reiterations in the cell lineages of C. elegans. Cell 24:59-69

12. Chalfie M, Sulston J (1981) Developmental genetics of the mechanosensory neurons of Caenorhabditis elegans. Dev Biol $82: 358-370$

13. Chalfie M, Sulston JE, White JG, Southgate E, Thomson JN, Brenner S (1985) The neural circuit for touch sensitivity in Caenorhabditis elegans. J Neurosci 5:956-964

14. Chalfie M, Thomson JN (1979) Organization of neuronal microtubules in the nematode Caenorhabditis elegans. J Cell Biol $82: 278-289$

15. Chalfie M, Thomson JN (1982) Structural and functional diversity in the neuronal microtubules of Caenorhabditis elegans. J Cell Biol 93:15-23

16. Chalfie M, Wolinsky E (1990) The identification and suppression of inherited neurodegeneration in Caenorhabditis elegans. Nature 345:410-416

17. Chelur DS, Ernstrom GG, Goodman MB, Yao CA, Chen L, R $\mathrm{OH}$, Chalfie M (2002) The mechanosensory protein MEC-6 is a subunit of the $C$. elegans touch-cell degenerin channel. Nature 420:669-673

18. Chiba CM, Rankin CH (1990) A developmental analysis of spontaneous and reflexive reversals in the nematode Caenorhabditis elegans. J Neurobiol 21:543-554

19. Colbert HA, Smith TL, Bargmann CI (1997) OSM-9, a novel protein with structural similarity to channels, is required for olfaction, mechanosensation, and olfactory adaptation in Caenorhabditis elegans. J Neurosci 17:8259-8269

20. Croll NA (1976) When Caenorhabditis elegans (Nematoda: Rhabditdae) bumps into a bead. Can J Zool 54:566-570

21. Driscoll M, Chalfie M (1991) The mec-4 gene is a member of a family of Caenorhabditis elegans genes that can mutate to induce neuronal degeneration. Nature 349:588-593

22. Du H, Chalfie M (2001) Genes regulating touch cell development in Caenorhabditis elegans. Genetics 158:197-207 
23. Du H, Gu G, William CM, Chalfie M (1996) Extracellular proteins needed for C. elegans mechanosensation. Neuron 16:183-194

24. Duggan A, Ma C, Chalfie M (1998) Regulation of touch receptor differentiation by the Caenorhabditis elegans mec-3 and unc-86 genes. Development 125:4107-4119

25. Emtage L, Gu G, Hartwieg E, Chalfie M (2004) Extracellular proteins organize the mechanosensory channel complex in $C$. elegans touch receptor neurons. Neuron 44:795-807

26. Finney M, Ruvkun G (1990) The unc-86 gene product couples cell lineage and cell identity in C. elegans. Cell 63:895905

27. Finney M, Ruvkun G, Horvitz HR (1988) The C. elegans cell lineage and differentiation gene unc- 86 encodes a protein with a homeodomain and extended similarity to transcription factors. Cell 55:757-769

28. Frokjaer-Jensen C, Kindt KS, Kerr RA, Suzuki H, MelnikMartinez K, Gerstbreih B, Driscol M, Schafer WR (2006) Effects of voltage-gated calcium channel subunit genes on calcium influx in cultured $C$. elegans mechanosensory neurons. J Neurobiol 66(10):1125-1139

29. Fukushige T, Siddiqui ZK, Chou M, Culotti JG, Gogonea CB, Siddiqui SS, Hamelin M (1999) MEC-12, an alpha-tubulin required for touch sensitivity in C. elegans. J Cell Sci $112(\mathrm{Pt}$ 3):395-403

30. Garcia-Anoveros J, Ma C, Chalfie M (1995) Regulation of Caenorhabditis elegans degenerin proteins by a putative extracellular domain. Curr Biol 5:441-448

31. Goodman MB, Ernstrom GG, Chelur DS, O’Hagan R, Yao CA, Chalfie M (2002) MEC-2 regulates C. elegans DEG/ENaC channels needed for mechanosensation. Nature 415:1039-1042

32. Goodman MB, Hall DH, Avery L, Lockery SR (1998) Active currents regulate sensitivity and dynamic range in C. elegans neurons. Neuron 20:763-772

33. Hamill OP, McBride DW Jr (1996) The pharmacology of mechanogated membrane ion channels. Pharmacol Rev 48:231252

34. Hilliard MA, Apicella AJ, Kerr R, Suzuki H, Bazzicalupo P, Schafer WR (2005) In vivo imaging of C. elegans ASH neurons: cellular response and adaptation to chemical repellents. EMBO J 24:63-72

35. Hodgkin J, Horvitz HR, Jasny BR, Kimble J (1998) C. elegans: sequence to biology. Science 282:2011

36. Hong K, Driscoll M (1994) A transmembrane domain of the putative channel subunit MEC-4 influences mechanotransduction and neurodegeneration in C. elegans. Nature 367:470-473

37. Hong K, Mano I, Driscoll M (2000) In vivo structure-function analyses of Caenorhabditis elegans MEC-4, a candidate mechanosensory ion channel subunit. J Neurosci 20:2575-2588

38. Huang M, Chalfie M (1994) Gene interactions affecting mechanosensory transduction in Caenorhabditis elegans. Nature 367:467-470

39. Huang M, Gu G, Ferguson EL, Chalfie M (1995) A stomatinlike protein necessary for mechanosensation in C. elegans. Nature 378:292-295

40. Huber TB, Schermer B, Muller, RU, Hohne, M, Bartram, M, Hagmann H, Reinhardt C, Calixto A, Koos F, Kunelmann K, Shirokova E, Krautwurst D, Harteneck C, Simons M, Pavenstadt H, Kerjaschki D, Thiele C, Walz G, Chalfie M, Benzing T (2006) Podocin and MEC-2 bind cholesterol to regulate the activity of associated ion channels. Proc Natl Acad Sci USA 103:17079-17086

41. Igarashi P, Somlo S (2002) Genetics and pathogenesis of polycystic kidney disease. J Am Soc Nephrol 13:2384-2398

42. Kaplan DD, Meigs TE, Kelly P, Casey PJ (2004) Identification of a role for beta-catenin in the establishment of a bipolar mitotic spindle. J Biol Chem 279:10829-10832
43. Kaplan JM, Horvitz HR (1993) A dual mechanosensory and chemosensory neuron in Caenorhabditis elegans. Proc Natl Acad Sci USA 90:2227-2231

44. Kellenberger S, Schild L (2002) Epithelial sodium channel/ degenerin family of ion channels: a variety of functions for a shared structure. Physiol Rev 82:735-767

45. Krishtal O (2003) The ASICs: signaling molecules? Modulators? Trends Neurosci 26:477-483

46. Kung C (2005) A possible unifying principle for mechanosensation. Nature 436:647-654

47. Lee RY, Sawin ER, Chalfie M, Horvitz HR, Avery L (1999) EAT-4, a homolog of a mammalian sodium-dependent inorganic phosphate cotransporter, is necessary for glutamatergic neurotransmission in Caenorhabditis elegans. J Neurosci 19:159-167

48. Li W, Feng Z, Sternberg PW, Xu XZ (2006) A C. elegans stretch receptor neuron revealed by a mechanosensitive TRP channel homologue. Nature 440:684-687

49. Liu DW, Thomas JH (1994) Regulation of a periodic motor program in C. elegans. J Neurosci 14:1953-1962

50. Liu J, Schrank B, Waterston RH (1996) Interaction between a putative mechanosensory membrane channel and a collagen. Science 273:361-364

51. Liu KS, Sternberg PW (1995) Sensory regulation of male mating behavior in Caenorhabditis elegans. Neuron 14:79-89

52. Lockery SR, Goodman MB (1998) Tight-seal whole-cell patch clamping of Caenorhabditis elegans neurons. Methods Enzymol 293:201-217

53. Lundquist EA, Herman RK, Rogalski TM, Mullen GP, Moerman DG, Shaw JE (1996) The mec-8 gene of C. elegans encodes a protein with two RNA recognition motifs and regulates alternative splicing of unc-52 transcripts. Development 122:1601-1610

54. Montell C, Birnbaumer L, Flockerzi V, Bindels RJ, Bruford EA, Caterina MJ, Clapham DE, Harteneck C, Heller S, Julius D, Kojima I, Mori Y, Penner R, Prawitt D, Scharenberg AM, Schultz G, Shimizu N, Zhu MX (2002) A unified nomenclature for the superfamily of TRP cation channels. Mol Cell 9:229-231

55. Nauli SM, Alenghat FJ, Luo Y, Williams E, Vassilev P, Li X, Elia AE, Lu W, Brown EM, Quinn SJ, Ingber DE, Zhou J (2003) Polycystins 1 and 2 mediate mechanosensation in the primary cilium of kidney cells. Nat Genet 33:129-137

56. O'Hagan R, Chalfie M (2006) Mechanosensation in Caenorhabditis elegans. Int Rev Neurobiol 69:169-203

57. O'Hagan R, Chalfie M, Goodman MB (2005) The MEC-4 DEG/ $\mathrm{ENaC}$ channel of Caenorhabditis elegans touch receptor neurons transduces mechanical signals. Nat Neurosci 8:43-50

58. Rankin CH (2000) Context conditioning in habituation in the nematode Caenorhabditis elegans. Behav Neurosci 114:496-505

59. Rankin CH (1991) Interactions between two antagonistic reflexes in the nematode Caenorhabditis elegans. J Comp Physiol A 169:59-67

60. Rankin CH, Beck CD, Chiba CM (1990) Caenorhabditis elegans: a new model system for the study of learning and memory. Behav Brain Res 37:89-92

61. Rankin CH, Broster BS (1992) Factors affecting habituation and recovery from habituation in the nematode Caenorhabditis elegans. Behav Neurosci 106:239-249

62. Rankin CH, Wicks SR (2000) Mutations of the Caenorhabditis elegans brain-specific inorganic phosphate transporter eat-4 affect habituation of the tap-withdrawal response without affecting the response itself. J Neurosci 20:4337-4344

63. Rose JK, Kaun KR, Chen SH, Rankin CH (2003) GLR-1, a nonNMDA glutamate receptor homolog, is critical for long-term memory in Caenorhabditiselegans. J Neurosci 23:9595-9599

64. Rose JK, Kaun KR, Rankin CH (2002) A new group-training procedure for habituation demonstrates that presynaptic gluta- 
mate release contributes to long-term memory in Caenorhabditis elegans. Learn Mem 9:130-137

65. Rose JK, Rankin CH (2001) Analyses of habituation in Caenorhabditis elegans. Learn Mem 8:63-69

66. Rose JK, Sangha S, Rai S, Norman KR, Rankin CH (2005) Decreased sensory stimulation reduces behavioral responding, retards development, and alters neuronal connectivity in Caenorhabditis elegans. J Neurosci 25:7159-7168

67. Royal DC, Bianchi L, Royal MA, Lizzio M Jr, Mukherjee G, Nunez YO, Driscoll M (2005) Temperature-sensitive mutant of the Caenorhabditis elegans neurotoxic MEC-4(d) DEG/ENaC channel identifies a site required for trafficking or surface maintenance. J Biol Chem 280:41976-41986

68. Sanyal S, Wintle RF, Kindt KS, Nuttley WM, Arvan R, Fitzmaurice P, Bigras E, Merz DC, Hebert TE, van der Kooy D, Schafer WR, Culotti JG, Van Tol HH (2004) Dopamine modulates the plasticity of mechanosensory responses in Caenorhabditis elegans. EMBO J 23:473-482

69. Savage C, Hamelin M, Culotti JG, Coulson A, Albertson DG, Chalfie M (1989) mec-7 is a beta-tubulin gene required for the production of 15-protofilament microtubules in Caenorhabditis elegans. Genes Dev 3:870-881

70. Sawin ER, Ranganathan R, Horvitz HR (2000) C. elegans locomotory rate is modulated by the environment through a dopaminergic pathway and by experience through a serotonergic pathway. Neuron 26:619-631

71. Schafer WR (2006) Proprioception: a channel for body sense in the worm. Curr Biol 16:R509-R511

72. Sedensky MM, Siefker JM, Morgan PG (2001) Model organisms: new insights into ion channel and transporter function. Stomatin homologues interact in Caenorhabditis elegans. Am J Physiol Cell Physiol 280:C1340-C1348

73. Shreffler W, Magardino T, Shekdar K, Wolinsky E (1995) The unc- 8 and sup- 40 genes regulate ion channel function in Caenorhabditis elegans motorneurons. Genetics 139:1261-1272

74. Sidi S, Friedrich RW, Nicolson T (2003) NompC TRP channel required for vertebrate sensory hair cell mechanotransduction. Science 301:96-99

75. Snyder PM, Bucher DB, Olson DR (2000) Gating induces a conformational change in the outer vestibule of ENaC. J Gen Physiol 116:781-790

76. Stewart GW, Argent AC, Dash BC (1993) Stomatin: a putative cation transport regulator in the red cell membrane. Biochim Biophys Acta 1225:15-25

77. Stewart GW, Hepworth-Jones BE, Keen JN, Dash BC, Argent AC, Casimir CM (1992) Isolation of cDNA coding for an ubiquitous membrane protein deficient in high $\mathrm{Na}+$, low $\mathrm{K}+$ stomatocytic erythrocytes. Blood 79:1593-1601

78. Sulston J, Dew M, Brenner S (1975) Dopaminergic neurons in the nematode Caenorhabditis elegans. J Comp Neurol 163:215-226

79. Sulston JE, Albertson DG, Thomson JN (1980) The Caenorhabditis elegans male: postembryonic development of nongonadal structures. Dev Biol 78:542-576

80. Sulston JE, Horvitz HR (1977) Post-embryonic cell lineages of the nematode, Caenorhabditis elegans. Dev Biol 56:110-156

81. Sulston JE, Schierenberg E, White JG, Thomson JN (1983) The embryonic cell lineage of the nematode Caenorhabditis elegans. Dev Biol 100:64-119

82. Suzuki H, Kerr R, Bianchi L, Frokjaer-Jensen C, Slone D, Xue J, Gerstbrein B, Driscoll M, Schafer WR (2003) In vivo imaging of C. elegans mechanosensory neurons demonstrates a specific role for the MEC-4 channel in the process of gentle touch sensation. Neuron 39:1005-1017

83. Tavernarakis N, Driscoll M (2000) Caenorhabditis elegans degenerins and vertebrate $\mathrm{ENaC}$ ion channels contain an extracellular domain related to venom neurotoxins. J Neurogenet 13:257-264

84. Tavernarakis N, Shreffler W, Wang S, Driscoll M (1997) unc-8, a $\mathrm{DEG} / \mathrm{ENaC}$ family member, encodes a subunit of a candidate mechanically gated channel that modulates C. elegans locomotion. Neuron 18:107-119

85. Tobin D, Madsen D, Kahn-Kirby A, Peckol E, Moulder G, Barstead R, Maricq A, Bargmann C (2002) Combinatorial expression of TRPV channel proteins defines their sensory functions and subcellular localization in $C$. elegans neurons. Neuron 35:307-318

86. Tsalik EL, Niacaris T, Wenick AS, Pau K, Avery L, Hobert O (2003) LIM homeobox gene-dependent expression of biogenic amine receptors in restricted regions of the C. elegans nervous system. Dev Biol 263:81-102

87. Vogel BE, Hedgecock EM (2001) Hemicentin, a conserved extracellular member of the immunoglobulin superfamily, organizes epithelial and other cell attachments into oriented line-shaped junctions. Development 128:883-894

88. Walker RG, Willingham AT, Zuker CS (2000) A Drosophila mechanosensory transduction channel. Science 287:2229-2234

89. Way JC, Chalfie M (1988) mec-3, a homeobox-containing gene that specifies differentiation of the touch receptor neurons in $C$. elegans. Cell 54:5-16

90. Way JC, Chalfie M (1989) The mec-3 gene of Caenorhabditis elegans requires its own product for maintained expression and is expressed in three neuronal cell types. Genes Dev 3:1823-1833

91. White JG, Southgate E, Thomson JN, Brenner S (1986) The structure of the nervous system of the nematode Caenorhabditis elegans. Philos Trans R Soc Lond 314:1-340

92. White JG, Southgate E, Thomson JN, Brenner S (1976) The structure of the ventral cord of Caenorhabditis elegans. Philos Trans R Soc Lond (Biol) 275:327-348

93. Wicks SR, Rankin CH (1995) Integration of mechanosensory stimuli in Caenorhabditis elegans. J Neurosci 15:2434-2444

94. Xue D, Finney M, Ruvkun G, Chalfie M (1992) Regulation of the mec-3 gene by the C. elegans homeoproteins UNC-86 and MEC-3. EMBO J 11:4969-4979

95. Xue D, Tu Y, Chalfie M (1993) Cooperative interactions between the Caenorhabditis elegans homeoproteins UNC-86 and MEC-3. Science 261:1324-1328

96. Yochem J, Bell LR, Herman RK (2004) The identities of sym-2, sym-3 and sym-4, three genes that are synthetically lethal with mec-8 in Caenorhabditis elegans. Genetics 168:1293-1306

97. Zhang S (2004) Stomatin gene family in Caenorhabditis elegans. Ph.D. thesis, Department of Biological Sciences, Columbia University, New York, New York

98. Zhang S, Arnadottir J, Keller C, Caldwell GA, Yao CA, Chalfie M (2004) MEC-2 is recruited to the putative mechanosensory complex in $C$. elegans touch receptor neurons through its stomatin-like domain. Curr Biol 14:1888-1896

99. Zhang Y, Ma C, Delohery T, Nasipak B, Foat BC, Bounoutas A, Bussemaker HJ, Kim SK, Chalfie M (2002) Identification of genes expressed in C. elegans touch receptor neurons. Nature 418:331-335

100. Zhao C, Emmons SW (1995) A transcription factor controlling development of peripheral sense organs in C. elegans. Nature 373:74-78 